\title{
Medicinal Product
}

National Cancer Institute

\section{Source}

National Cancer Institute. Medicinal Product. NCI Thesaurus. Code C142605.

Any substance or combination of substances that may be administered to human beings (or animals) for treating or preventing disease, or with the intent to make a medical diagnosis or to restore, correct or modify physiological functions. (IDMP) 